\title{
EFFECTS OF THE COMPOSITE STACKING SEQUENCE ON THE FAILURE LOAD OF THE SINGLE LAP BONDED JOINT
}

\author{
MOHAMed MOKHTARI \\ Laboratoire de la Recherche en Technologie de Fabrication Mécanique, Ecole Nationale Polytechnique of Oran, \\ Oran, Algeria; e-mail: mokhtarimohamed44@yahoo.fr \\ KOUIDER MADANi \\ Laboratoire Mécanique Physique des Matériaux (LMPM), University of Sidi Bel Abbes, Sidi Bel Abbes, Algeria \\ e-mail: koumad10@yahoo.fr
}

HABIB BENZAAMA

Laboratoire de Biomécanique Appliquée et de Biomatériaux, Ecole Nationale Polytechnique of Oran, Oran, Algeria e-mail: habenza@yahoo.fr

Stephanie Malarino

Laboratoire des Sciences de l'Ingénieur pour l'Environnement, Université de La Rochelle, La Rochelle, Cedex, France e-mail: stephanie.mallarino@univ-lr.fr

\begin{abstract}
Composite materials are widely used in aircraft structures, their relative rigidity/weight confers their advantage over metal structures, and the stacking sequence plays an important role for their use. The objective of this work is to analyze by the finite element method the mechanical behavior of a single lap joint of composite/composite type under a tensile load. In order to see the effects on the failure load, two basic parameters are taken into consideration; the stacking sequence of composite and thickness of each layer constituting the composite. Calculation of the failure load is made numerically with the ABAQUS code using the developed technique of VCCT (Virtual Crack Closure Technique) based on fracture mechanics. Finally, the influence of the bonding defect on the failure load is analyzed. The results clearly show the importance of optimizing fiber orientation and hence the stacking sequence for proper use of composite in bonded assemblies.
\end{abstract}

Keywords: Virtual Crack Closure Technique (VCCT), laminate sequence, single lap joint, bonding defect

\section{Introduction}

Single lap joints are widely used, in particular, in aeronautics. Their main problem is the non-uniform stress distribution in the adhesive joint. These stresses are concentrated at the edges of the adhesive. This concentration is usually due to misalignment of two forces that engender creation of additional stresses at the edges of the bending moment, which causes subsequent joint failure. The behavior analysis of the assembly leads directly to the analysis of mechanical behavior of the adhesive by determination of stresses in the adhesive joint and the adhesive/composite interface.

Several authors analyze stresses in the adhesive by analytical methods, see Adams et al. (1986), to estimate the response of the adhesive against the applied load. Others have extended their research to analyze the stress distribution by numerical methods, Tsai et al. (1995), to vary more mechanical and geometric parameters influencing the adhesive durability. The effect of the nature of materials to be assembled on the bonding strength of single lap joints is still not fully 
understood. Conventional elastic analyzes predict that the resistance increases with strength of the adherent, and experimental results confirm this.

The analysis of breakdown of composite laminate or composite bonded joints is essential to ensure a long structure life, see Shiming et al. (2011), Ray and Majamuder (2014) and Liu et al. (2015). It has led researchers to use more effective methods, namely the Virtual Crack Closure Technique (VCCT), the eXtended Finite Element Methods (XFEM) and the Cohesive Zone Method (CZM).

The Virtual Crack Closure Technique (VCCT) is a well-established method for calculating the energy release rate (ERR) when analysing fracture problems through the finite element method (FEM). The technique is based on the numerical implementation of Irwin (1958). The crack closure integral was first proposed for two-dimensional problems by Rybicki and Kanninen (1977), and later extended to three-dimensional problems by Shivakumar et al. (1988). In the recent years, the VCCT has gained great popularity in the study of mixed-mode fracture problems such as delamination of composite materials and interfacial fracture between dissimilar materials. In these cases, the VCCT is used to compute not only the total ERR, but also the contributions of three fracture modes (I or opening, II or sliding and III or tearing) Krueger (2004).

A comprehensive review of VCCT formulae for different element types was given by Krueger (2004) and Whitcomb (1989) who were first to introduce the use of the VCCT to determine ERR for circular delamination. Since then, a lot of numerical analyses have been performed by using this technique, many of them dealing with initiations and growth of delamination, see Mukherjee et al. (1994), others with growth evolution, Klug et al. (1996).

The Virtual Crack Closure Technique (VCCT) is a fracture analysis method that is typically used when plastic dissipation does not exist. More recently, several researchers have developed this method in their failure analysis in composite structures, namely composite materials and bonded assemblies.

Delamination can be assimilated to a fracture process between anisotropic layers (interlaminar damage). Thus, fracture mechanics principles by Janssen et al. (2004) can be used to study behaviour of composite structures in presence of interlaminar damage and to determine conditions for the initiation and growth of delamination. If the delamination growth process is considered as a crack propagation phenomenon, fracture mechanics concepts can be generally transferred to the analysis of delaminated composite structures. The propagation of a crack is possible when the energy released for a unit width and length of the fracture surface (named Strain Energy Release Rate, G) is equal to a threshold level or fracture toughness, characteristic for each material, see Janssen Zuidema et al. (2004).

Jokinen et al. (2015) studied the applicability of VCCT for crack growth analyses of a bonded joint with a ductile adhesive and self-similar crack growth. Their analyses were performed for a Double Cantilever Beam (DCB) specimen with epoxy adhesive. Their force-displacement curve matched well with the experimental data.

Shokrieh et al. (2012) proposed new finite element methods for modeling the crack growth taking into account the Timoshenko beam element with only displacement degrees of freedom addressed for laminated composite beams. Then, they proposed a finite element procedure for simulation of mode I delamination growth in symmetric multidirectional double cantilever beam (DCB) specimens based on the fracture mechanics using the above-mentioned element. A variable strain energy release rate was used instead of constant initiation fracture toughness. The strain energy release rate was computed using Virtual Crack Closure Technique (VCCT) method. Their results of the finite element simulation corresponded well with the experimental data available in the literature.

Ahn and Woo (2015) presented in their paper the p-convergent partial discrete-layer elements with the Virtual Crack Closure Technique (VCCT) for delamination analysis of laminated com- 
posite plates. The proposed element could be formulated by suitable dimensional reduction from a three-dimensional solid to a two-dimensional plate. The three-dimensional VCCT was also slightly modified to incorporate with the proposed elements and estimate the energy release rate. Then for fracture analysis, the efficiency of their proposed approach was demonstrated with the help of two additional problems such as the double cantilever beam test and the orthotropic laminated square plate with interior delamination.

The objective of this study is to analyze numerically the effect of composite stacking sequence on the resistance of an assembly of composite/composite type. Six stacking sequences for the laminate have been selected in order to see the effect of fiber orientation on the failure load of the joint. Different values of fracture energy of the adhesive have been proposed in order to see their effect on the assembly failure load value. The thickness effect of the composite ply on the assembly failure load value has been highlighted. For this, four thickness values of various layers of the composite have been studied, namely, $0.125,0.2,0.25$ and $0.3 \mathrm{~mm}$, and that for each stacking sequence of laminate plates. The analysis of the numerical results show that the failure load increases as the laminated plate has high strength.

\section{Description of model geometry and material properties}

The objective of this study is to determine, by a three-dimensional numerical analysis, the failure load for a single lap joint of composite/composite type under tensile load as shown in Fig. 1. The dimensions of the two substrates and the adhesive are shown in Table 1. The composite is of carbon/epoxy type. Its mechanical properties are shown in Table 2.

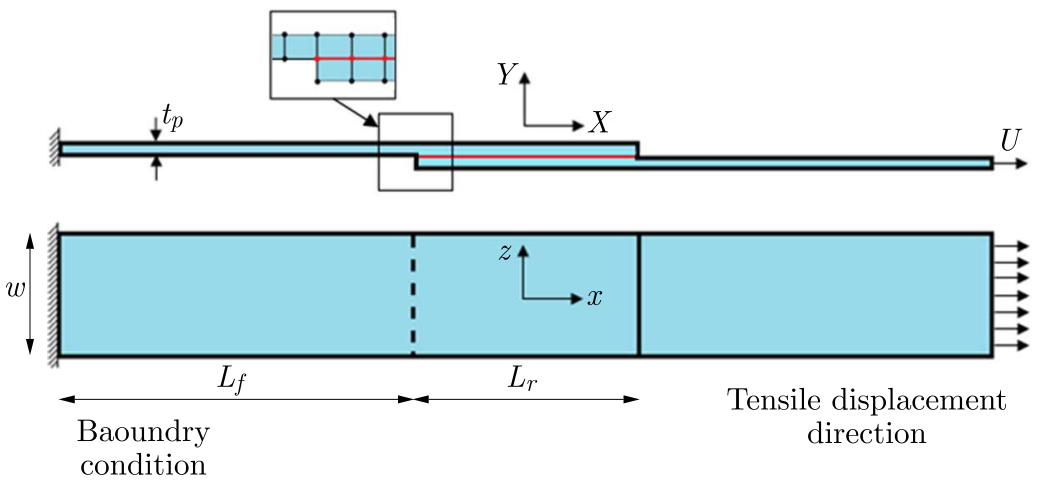

Fig. 1. Single lap joint geometry

Table 1. Dimensions of different layers of a single lap joint

\begin{tabular}{|l|c|}
\hline Thickness of lower and upper parent laminate & $t_{p}=2 \mathrm{~mm}$ \\
\hline Free length of parent laminate & $L_{f}=60 \mathrm{~mm}$ \\
\hline Overlap length & $L_{r}=20 \mathrm{~mm}$ \\
\hline Wide of parent laminate & $w=15 \mathrm{~mm}$ \\
\hline Applied tensile displacement & $U=2 \mathrm{~mm}$ \\
\hline
\end{tabular}

Table 2. Mechanical properties of the used laminates, Campilho et al. (2005)

\begin{tabular}{|c|c|c|}
\hline$E_{1}=1.09 \mathrm{E}+05 \mathrm{MPa}$ & $\nu_{12}=0.342$ & $G_{12}=4315 \mathrm{MPa}$ \\
\hline$E_{2}=8819 \mathrm{MPa}$ & $\nu_{13}=0.342$ & $G_{13}=4315 \mathrm{MPa}$ \\
\hline$E_{3}=8819 \mathrm{MPa}$ & $\nu_{23}=0.380$ & $G_{23}=3200 \mathrm{MPa}$ \\
\hline
\end{tabular}

$E$ - Young's modulus, $\nu$ - Poisson's ratio, $G$ - shear modulus 
The adhesive used for bonding is Araldite 420, its tensile curve is represented in Fig. 2. The different mechanical properties of the adhesive are given in Table 3 and taken directly from the literature, see de Moura et al. (2006). This adhesive is used also in the aerospace industry given its important mechanical characteristics.

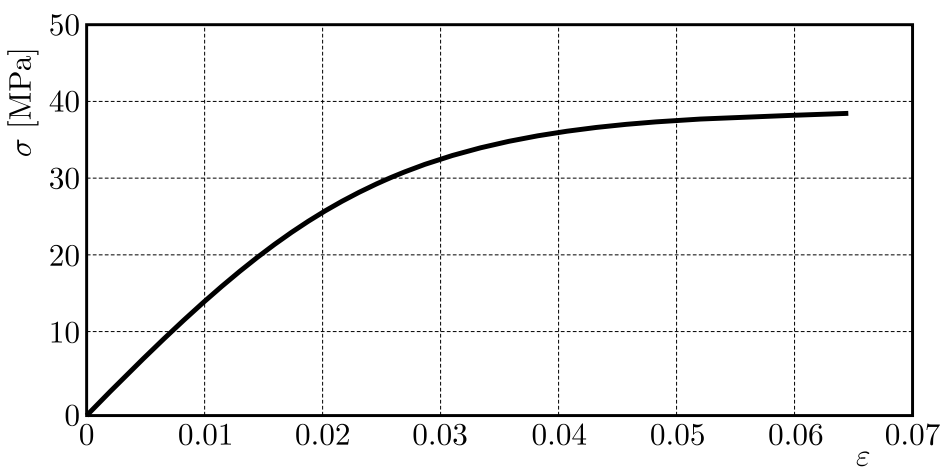

Fig. 2. Stress-strain relationship of Araldite®420adhesive (de Moura et al., 2006)

Table 3. Elastic, strength and fracture properties of the used adhesive (de Moura et al., 2006); $\sigma u_{, I}, \sigma u_{, I I}$ - local strength in mode I and II, respectively, $G_{I C}, G_{I I C}$ - critical strain energy release rate in mode I and II, respectively

\begin{tabular}{|c|c|c|}
\hline Elastic & Strength & Fracture energy \\
\hline \hline$E=1850 \mathrm{MPa}$ & $\sigma u_{, I}=40 \mathrm{MPa}$ & $G_{I C}=0.3 \mathrm{~N} / \mathrm{mm}$ \\
\hline$\nu=0.3$ & $\sigma u_{, I I}=24.1 \mathrm{MPa}$ & $G_{I I C}=0.6 \mathrm{~N} / \mathrm{mm}$ \\
\hline
\end{tabular}

Different ply orientations of the composite adherent are considered in this study to investigate their effect on the failure load. The value of $\theta$ (orientation angle) is measured from the longitudinal direction of the structure ( $x$-axis) and varied from $0^{\circ}$ to $90^{\circ}$ (Table 4 ). Then, in the second case, a change of thickness of the layer which has fiber orientation except for $0^{\circ}$ and $90^{\circ}$ (Fig. 3) is introduced. All layers have the same matrix (epoxy) and the same fiber materials (carbon).

The numbers $1,2, \ldots, 6$ show the laminate type chosen in the $x$-axis of different curves. The laminate type is presented in Table 4.

Table 4. Different ply orientations used in analyses (Campilho et al., 2005)

\begin{tabular}{|l|l|}
\hline Laminate $1-\left(0_{8}\right)_{S}$ & Laminate $4-\left(0_{2} / 45_{2} / 45_{2} / 90_{2}\right)_{S}$ \\
\hline Laminate $2-\left(0_{2} / 15_{2} /-15_{2} / 90_{2}\right)_{S}$ & Laminate $5-\left(0_{2} / 60_{2} /-60_{2} / 902\right)_{S}$ \\
\hline Laminate $3-\left(0_{2} / 30_{2} /-30_{2} / 902\right)_{S}$ & Laminate $6-\left(0_{2} / 75_{2} /-75_{2} / 90_{2}\right)_{S}$ \\
\hline
\end{tabular}

To simulate the crack onset and it is growth as well as to obtain the failure load associated with delamination of the bonded area, linear behaviour of the materials has been assumed using shell elements and a 4-node plain part. Figure 6 shows a detail of the mesh used at the lower and upper bonded edge. The adhesive has been modeled as an interface where it is necessary to introduce the mechanical parameters listed in Table 2. The delamination has been modeled between the lower and upper plate using two superimposed shell elements with contact constraint defined to prevent penetration of the elements.

The debonding has been simulated in the finite element model by maintaining merged nodes on the two adjacent faces of the overlap region (adhesive/composite). It is necessary to have an appropriate number of the mesh member in the overlap region since this modeling approach is based on the number of nodes. When the number of nodes increases, the failure load value decreases to a steady value regardless of the increase in the number of nodes (approximately 

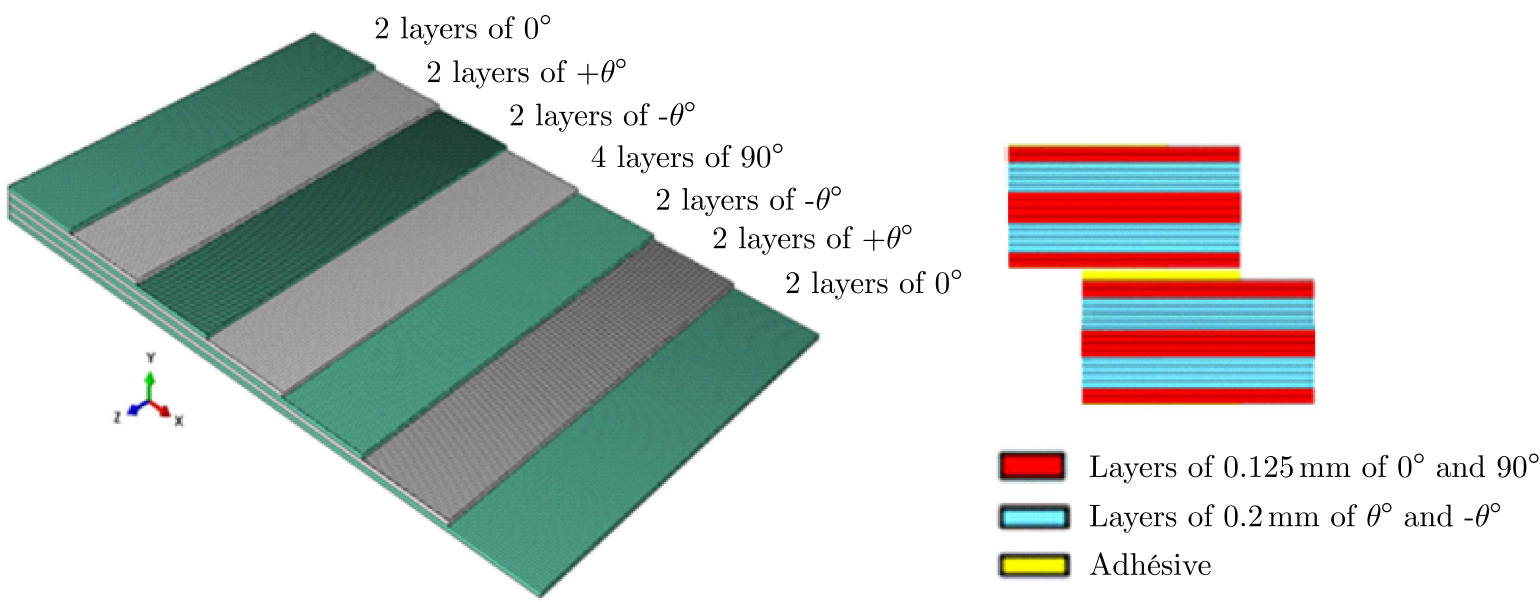

Fig. 3. Stacking sequence as function of layer thickness

6800 nodes in the overlapping area). However, the interlaminate failure of the plate has not been considered in this analysis in order to promote only the separation between plates as it was verified by several authors (Adkins and Pipes, 1988; Kumar et al., 2006).

Delamination is merely debonding between two adjacent parts of the same structure along thickness. This debonding can be simulated in the finite element method by maintaining not merged nodes on two adjacent faces of the volumes or surfaces representing respectively two sublaminates (Fig. 4).

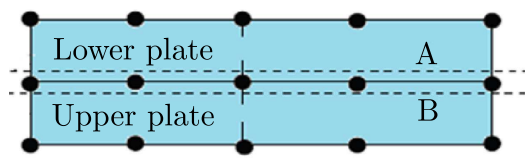

Coincident but not merged nodes
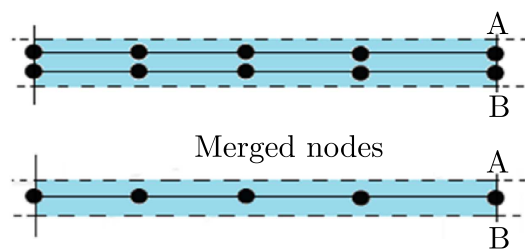

Fig. 4. Delamination simulated by maintaining not merged nodes with identical coordinates belonging to adjacent elements

The two layers of elements are tied at the interface during the loading. It should also be noted that some concerns have been raised, mainly related to the convergence of the model by introducing regular viscosity for an adequate time increment.

The interfacial properties which ensure the adhesion between the laminate plates are assigned to the nodes, the more the node number increases, the more the interfacial energy decreases to an optimal number when the separation energy is independent of the number of nodes (see Fig. 5).

\section{Effect of stacking sequence and layers thickness of the laminate plate}

In bonded assemblies, the stress distribution in the adhesive joint is heterogeneous. The edges are always overstretched while the heart of the adhesive is generally inactive. Whether participants 


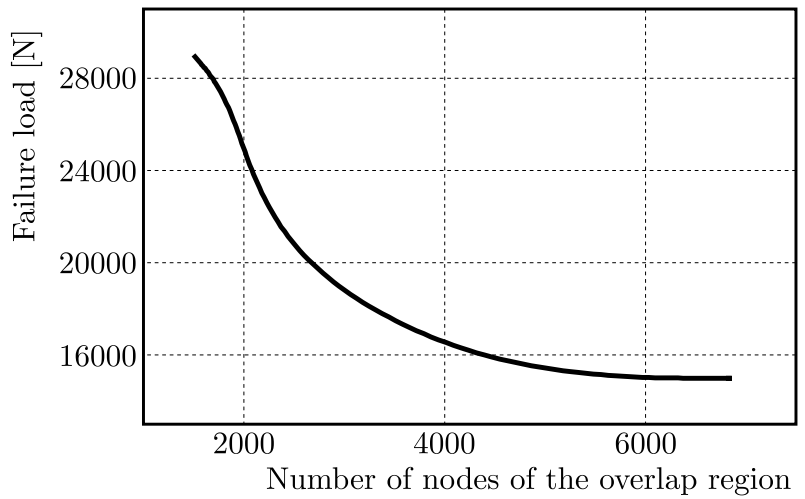

Fig. 5. Mesh convergence of the merged nodes in the interface using VCCT

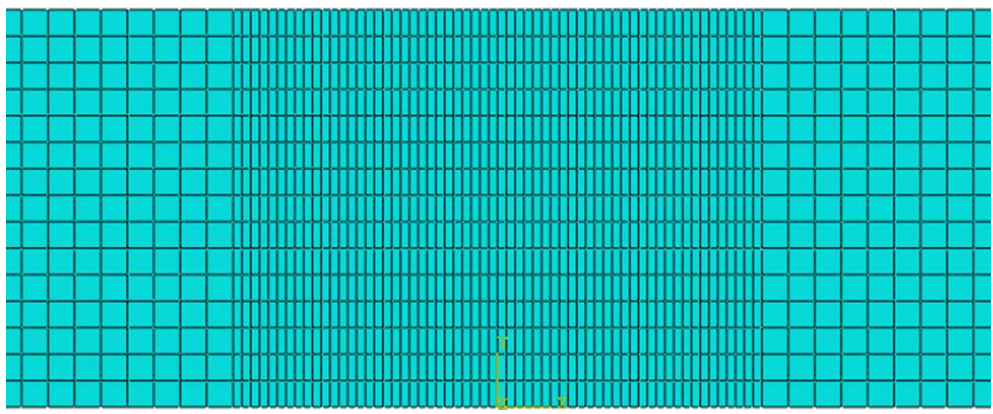

Fig. 6. Detail of the mesh at the bonded region

(composite) are too rigid, much of the applied load is transmitted to the adhesive layer and the fracture will be located at the edges of the adhesive.

The finite element analysis allows one to simulate the traction-separation of a single lap joint using the VCCT method.

A change in fiber orientation of the composite modifies its resistance and, therefore, minimizes the charge transfer to the adhesive. The objective is to see how the stiffness of the composite (stacking sequence) can affect the fracture load value of the overall assembly.

Interface finite elements are placed at the same locations to enable simulation of the crack onset and its growth, and predict the joint strength under the mixed failure mode. In all cases, an interfacial failure has been observed. Failure onset occurs at the interface starting in the borders of the covering surface. This fact is explained by highly pronounced stresses (shear and peel peaks) at these locations. This overstress peak becomes wider in the presence of defect bonding, especially at the edges of the adhesive.

Figure 7 presents the fracture load for different stacking sequences of the laminate composite. According to the analysis results in Fig. 7, the failure load is controlled by the rigidity of the assembled plates and the bonding surface.

In our analysis, the stiffness is not only due to the composite (Mokhtari et al., 2013; Campilho et al., 2005), but it is the composite/adhesive/composite stiffness. Figure 7 shows the composite/adhesive/composite stiffness during loading for each laminate.

For a unidirectional composite in which individual layers have the same orientation of the fibers and parallel to the direction of the applied load, the stiffness of the composite is very elevated and, therefore, the structure (composite/adhesive/composite) gets a minimum ductility ensuring a high failure load and a minimum displacement. However, if the plates are less rigid, the displacement is greater and, therefore. the tensile strength is less important.

So the failure load is controlled by the rigidity of the assembled plate. The more ductile the plates are, the greater is the elongation and, therefore, the lower is the failure load. In our 


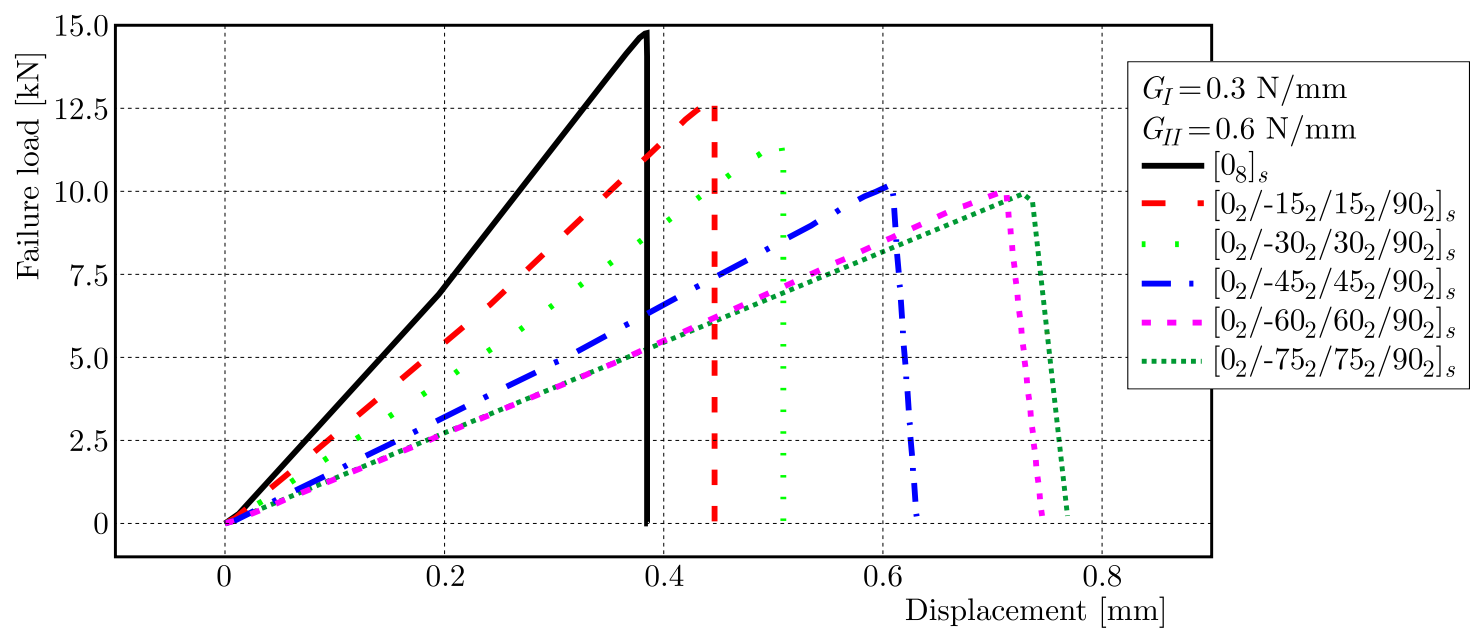

Fig. 7. Failure load-displacement curves for different stacking sequences of Carbon-Epoxy laminate
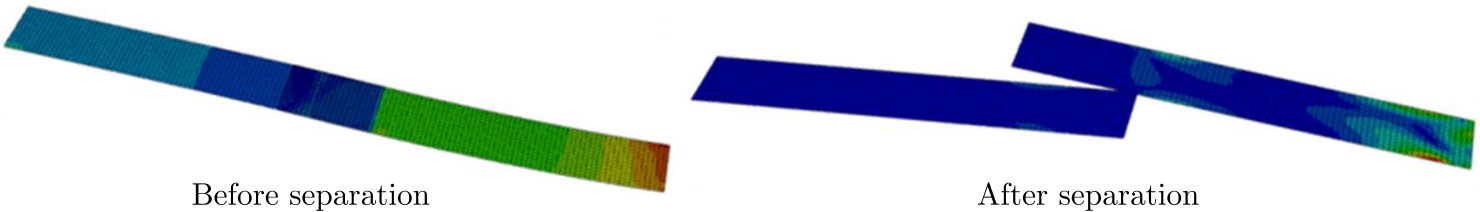

After separation

Fig. 8. Interfacial failure of the bonded joint

study, the stiffness of the plates is explained by orientation of the fibers relative to the loading axis (stacking sequence effect), which also explains the rapid separation with the load failure. However, for laminate 2, 3 and 4, the stacking sequence have some effect on the results in contrast to laminates $5\left(0_{2} / 60_{2} /-60_{2} / 90_{2}\right)_{S}$ and $6\left(0_{2} / 75_{2} /-75_{2} / 90_{2}\right)_{S}$, where the results are very similar, so the effect is much less.

A change in the composite fiber orientation modifies its mechanical properties which affects directly the charge transfer to the adhesive and thus the assembly rupture. If thickness of the plies forming the composite is changed, the composite is consolidated gradually and hence its section increases. Therefore, more energy is necessary to deform the assembly and thus fracture load will be higher. The more ply thickness increases, the more the separation force increases, and this applies to all stacking sequences.

\section{Effect of fracture energy and layers thickness of the laminate plate}

Different composite bonded systems can have significantly different fracture energies (Varughese and Mukherjee, 1997). So, it is appropriate to investigate whether variation of this parameter will affect the predicted failure mechanisms and loads. The fracture energies $G_{I}$ and $G_{I I}$ are varied but the ratio of $G_{I}$ to $G_{I I}$ is kept constant. Other parameters are fixed at the baseline values given in Tables 3. Figure 9 summarizes the effect of fracture energy on the predicted tensile failure load.

From Figs. 10 and 11, it should be noted that if the fracture energy increases, the assembly resistance becomes higher, leading to a longer lifetime. The magnitude of this resistance varies with the variation of the stacking sequence specifically with fiber orientation. The combination of high breaking energy and stacking sequence for which the fiber orientation is less than $45^{\circ}$ gives the assembly with high fracture load.

Changing the thickness of the composite ply generates a great resistance to the composite and thus difficult transfer load to the adhesive and, therefore, high fracture load. 


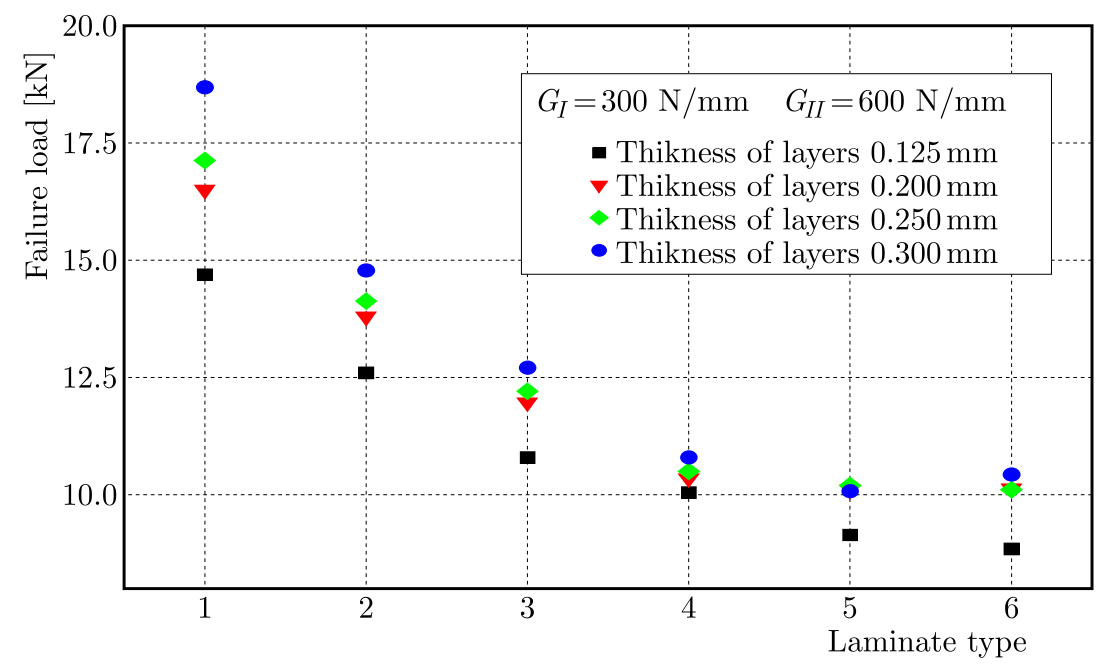

Fig. 9. Failure load as a function of layer thickness for each stacking sequence

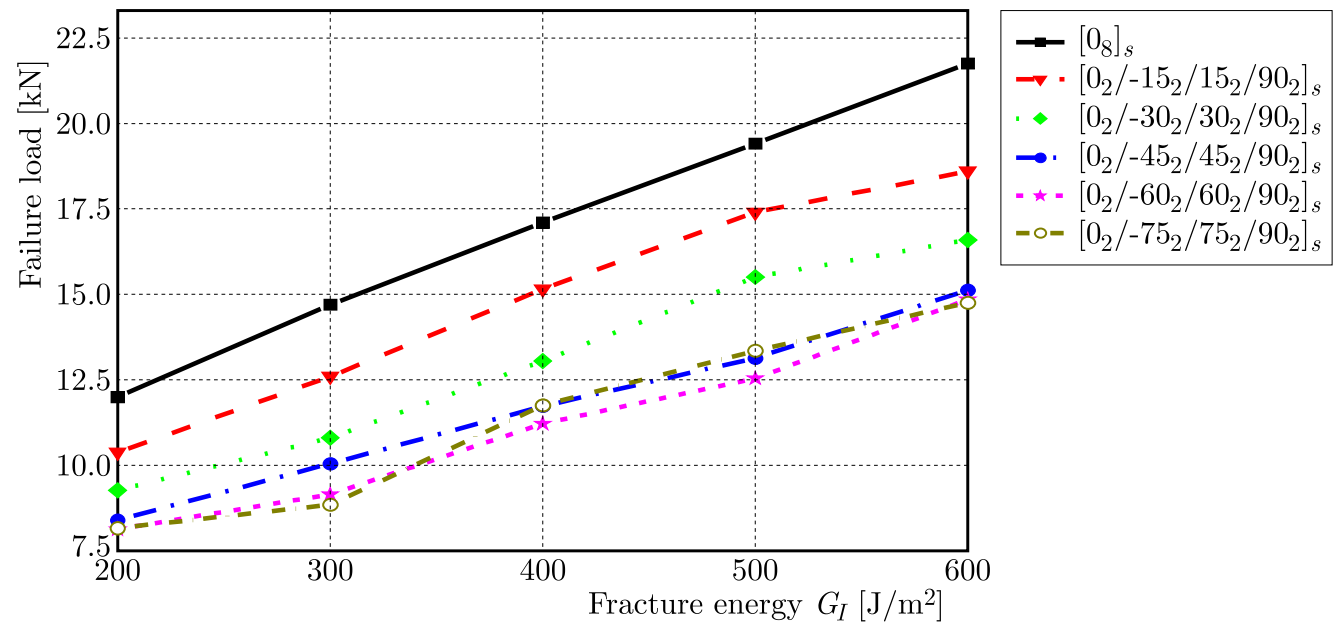

Fig. 10. Failure load as a function of fracture energy for different stacking sequences (ply thickness of $0.125 \mathrm{~mm}$ )

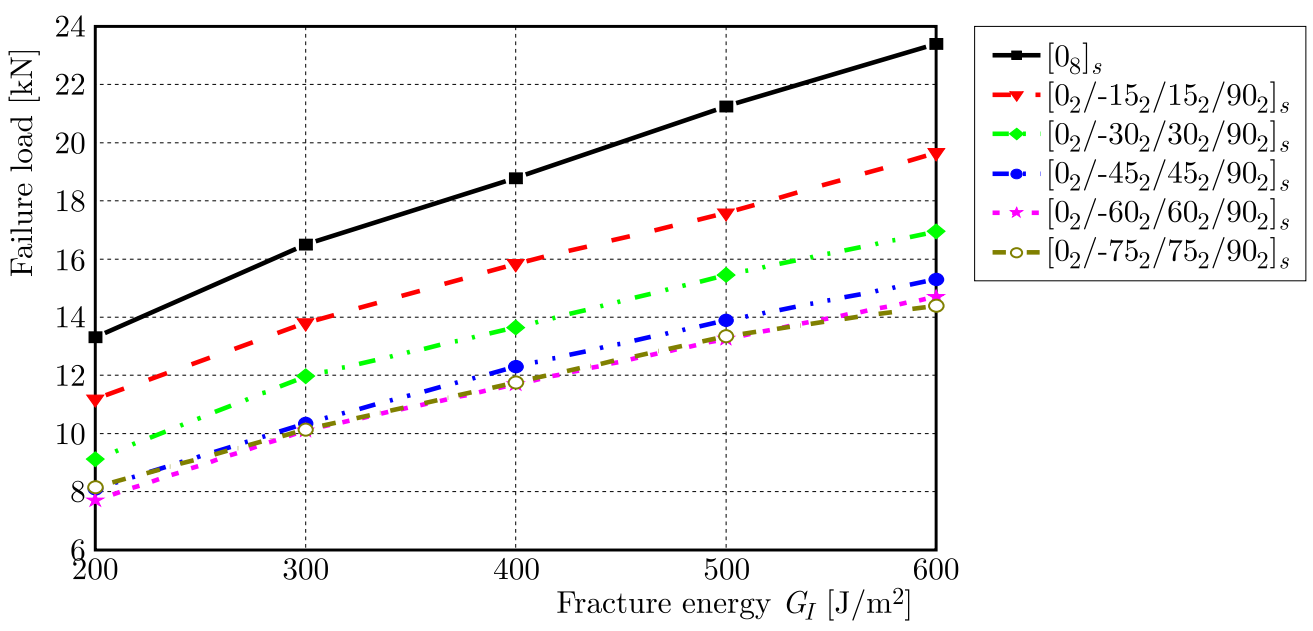

Fig. 11. Failure load as a function of fracture energy for different stacking sequences (ply thickness of $0.2 \mathrm{~mm}$ ) 


\section{Effect of bonding defect on the failure load}

Most of the research in the bonding area has not considered the presence of bonding defects in numerical calculations. However, at the end of the stage of implementation of bonded joints, various defects are likely to be created at different areas of the overlap length. The presence of porosities in the adhesive joint can be created due to volatile compounds evaporation and/or the existence of trapped air bubbles during the curing. It is obvious that these types of defects are prime areas for degradation of the interface by introduction of water or oxygen. More recently, Karachalios et al. (2013), Shishesaz and Bavi (2013), and Benchiha and Mandi (2015) analyzed the resistance of a bonded lap joint in the presence of defect by experimental, numerical and analytical methods. Their results showed that the resistance of the assembly was associated to the position and size of the defect.

In this part of the work, the effect of presence of a circular defect (diameter of $2 \mathrm{~mm}$ ) is studied for seven different possible positions (Fig. 12).
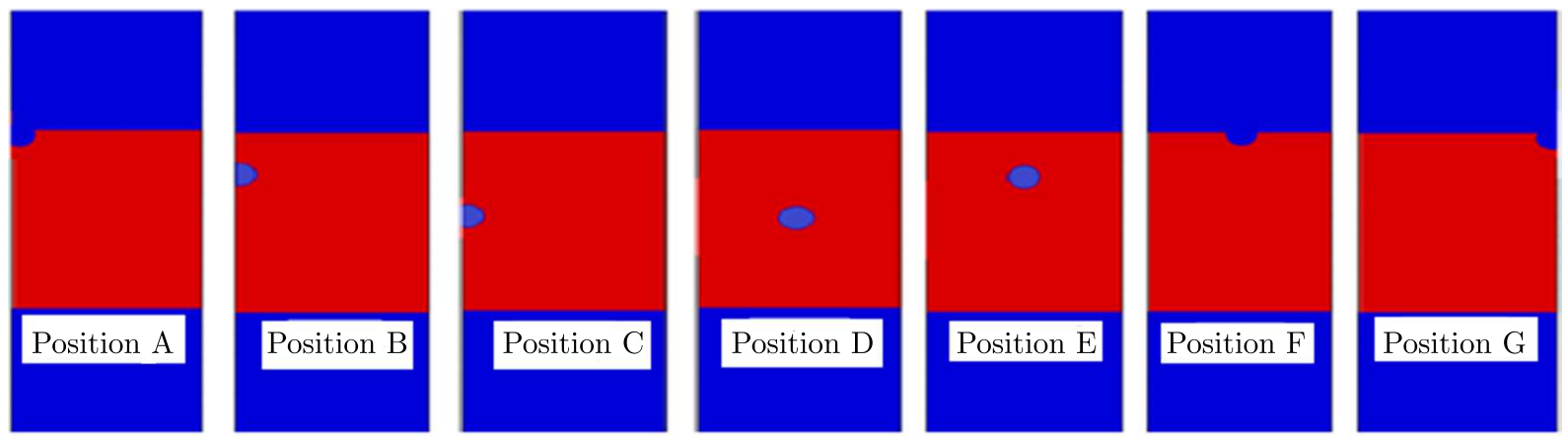

Fig. 12. Different positions of defect

Figure 13 shows the mesh for each defect position. The results of the value of the breaking load are very sensitive to the mesh since the method is based on the number of nodes at the level of the overlap zone. It is also important to ensure the same mesh for the plates, especially at the position of the defect. For all cases, it has been observed that separation of two plates begins at the defect location, especially when the latter is placed near the free edge.
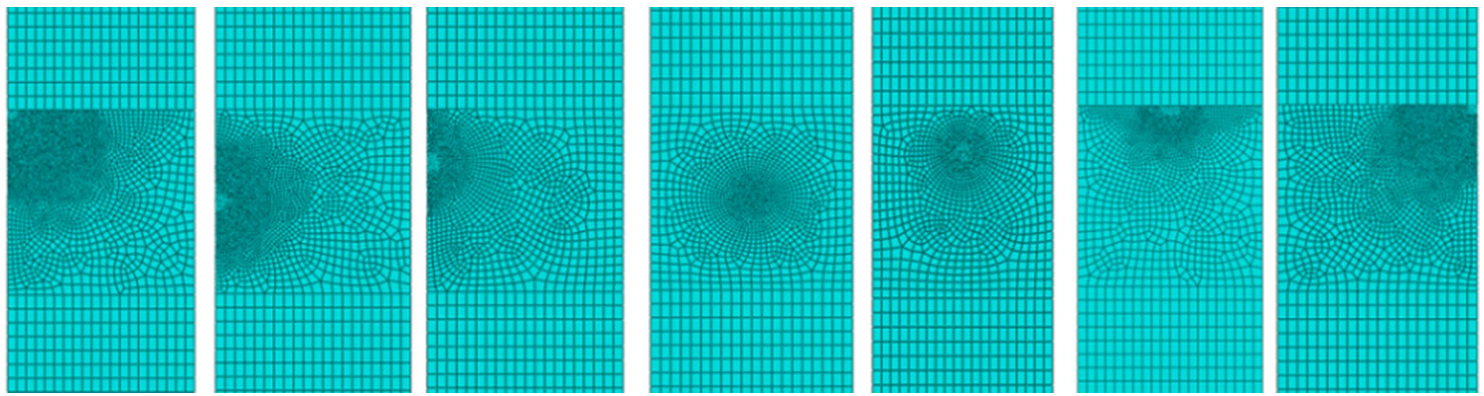

Fig. 13. Detail of the mesh at the region of the bond area for different positions of defects

The architecture of the mesh follows the location of the defect, and the number of nodes is checked at each analysis. Figure 5 illustrates the effect of the number of nodes on the results.

If the defect is in the middle of the adhesive (position $D$ ), the breaking strength value will not be affected by this position, but by the stacking sequence.

If the defect is on the free edge of the adhesive, it may have a more serious effect on the breaking strength value, leading to easy separation of the two substrates. If the material stiffness 
is high and the defect is on the free edge of the adhesive, the value of the failure load decreases considerably (the case of stacking sequence and orientation of fibers less than $45^{\circ}$ ).

(a)
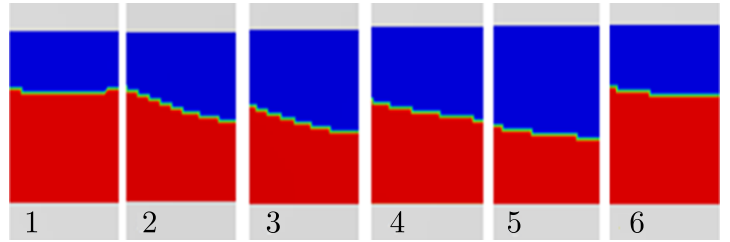

(b)
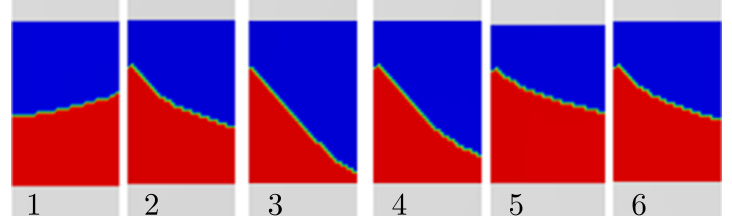

(c)
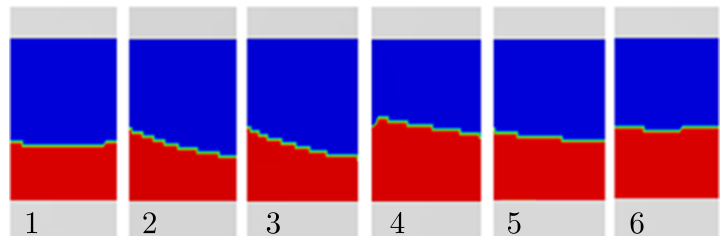

(d)
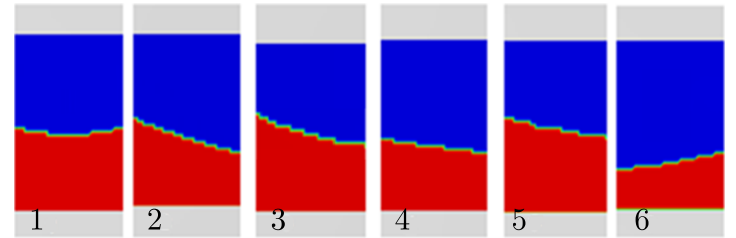

(e)
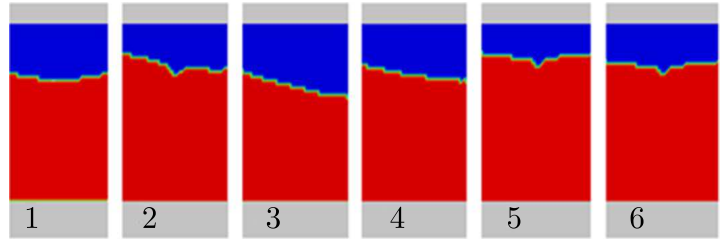

(f)
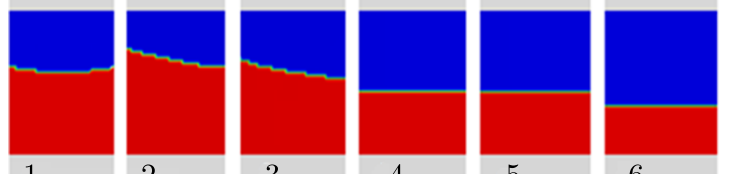

(g)

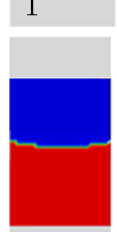

1
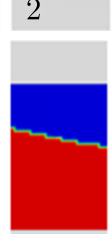

2

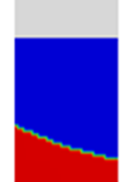

3

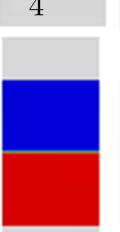

4

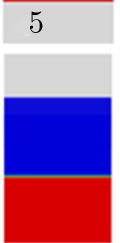

5

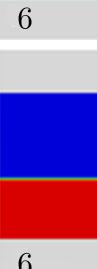

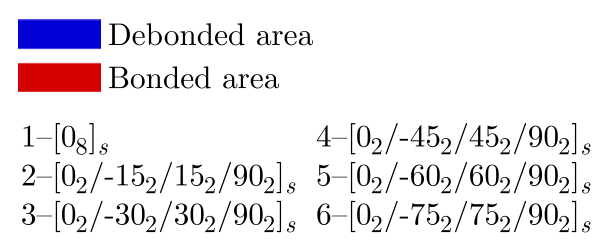

Fig. 14. Debonding area as a function of the stacking sequence and different positions of defects

Figure 15 shows that the defect presence decreases the fracture load. This decrease is remarkable for stack $0^{\circ}$ (laminate1) and becomes smaller with the increasing angle of fiber orientation. Therefore, the plate rigidity in the loading direction focuses the defect effect on the separation load, when comparing the effect of defect position. We find that it is more pronounced and may go up until $1 \mathrm{KN}$ except for some stacks $\left(0_{2} / 75_{2} /-75_{2} / 90_{2}\right)$ and $\left(0_{2} / 75_{2} /-75_{2} / 90_{2}\right)$. Figure 15 presents delaminations paths for different bonding defect positions and stacking sequences. The delamination path depends both of the defect position and the stacking sequence. 


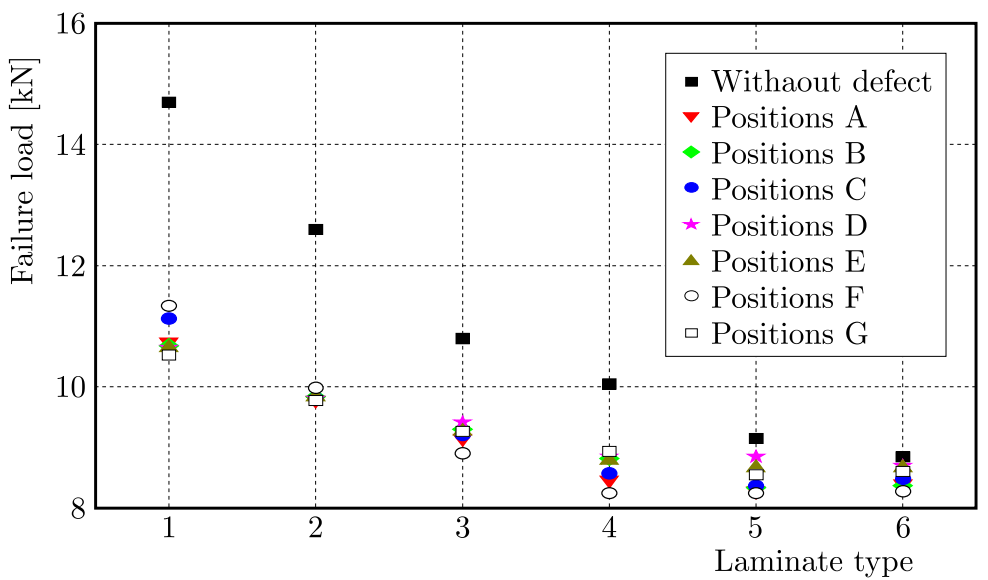

Fig. 15. Failure load as a function of different positions of defects for each stacking sequence

\section{Conclusion}

This study has been focused on numerical simulation based on the Virtual Crack Closure Technique (VCCT) of a single lap joint with and without the presence of the bonding defect. The following conclusions could be deduced from the obtained results:

- VCCT technique has been used to estimate the failure load value of two composite substrates.

- The failure load value is directly related to stiffness of the material. If the material is more rigid, the failure load value is elevated, but the displacement decreases.

- An increase in thickness of different layers increases rigidity of the composite plate and, consequently, increases the failure load.

- Fiber orientation plays a crucial role on the composite mechanical properties. If the fiber orientation is parallel to the traction direction, the composite acquires high rigidity and, therefore, a significant failure load.

- If the fiber orientation angle exceeds $45^{\circ}$, the material stiffness decreases and the elongation is more important for the plates in the longitudinal axis of the load, which decreases the failure load.

- If energy separation $G_{I}$ increases, the failure load increases.

- The failure load considerably decreases with variation of the adhesive separation energy and stacking sequence of the composite if the adhesive has a bonding defect.

\section{References}

1. Adams R., Atkins R., Harris J., Kinloch A., 1986, Stress analysis and failure properties of carbon-fibre reinforced plastic/steel double lap-joint, Journal of Ahdesives, 20, 29-30

2. Adkins D.W., Pipes R.B., 1988, Tensile behaviour of bonded scarf joints between composite adherend, Proceedings of the Fourth Japan - US Conference on Composite Materials, 845-854

3. Ahn J.S., Woo K.S., 2015, Delamination of laminated composite plates by p-convergent partial discrete-layer elements with VCCT, Mechanics Research Communications, 66, June, 60-69

4. Benchina A., Madani K., 2015, Influence of the presence of defects on the stresses shear distribution in the adhesive layer for the single-lap bonded joint, Structural Engineering and Mechanics, $\mathbf{5 3}, 5,1017-1030$

5. Campilho R., De Moura M.F.S.F, Domingues J.J.M.S., 2005, Modelling single and doublelap repairs on composite materials, Composites Science and Technology, 65, 1948 
6. De Moura M.F.S.F., Daniaud R., Magalhães A.G., 2006, Simulation of mechanical behaviour of composite bonded joints containing strip defects, International Journal of Adhesion and Adhesives, 26, 464-473

7. IRwin G.R., 1958, Fracture, [In:] Handbuch der Physik, Flugge S., (Ed.), vol. VI, Springer, Berlin, 551-590

8. Janssen M., Zuidema J., Wanhill R.J.H., 2004, Fracture Mechanics, Spon Press Taylor \& Francis, ISBN 0415346223

9. Jokinen J., Wallin M., SaArela O., 2015, Applicability of VCCT in mode I loading of yielding adhesively bonded joints - a case study, International Journal of Adhesion and Adhesives, 62, October, 85-91

10. Karachalios E.F., Adams R.D., DA Silva L.F.M., 2013, Strength of single lap joints with artificial defects, International Journal of Adhesion and Adhesives, 45, 69-76

11. Klug J., Wu X., Sun C.T., 1996, Efficient modeling of postbuckling delamination growth in composite laminates using plate elements, AIAA Journal, 34, 178-184

12. Krueger R., 2004, The virtual crack closure technique: history, approach and applications, Applied Mechanics Reviews, 57, 2, 109-143

13. Kumar S.B., Sridhar I., Sivashanker S., Osiyemi S.O., Bag A., 2006, Tensile failure of adhesively bonded CFRP composite scarf joints, Materials Science and Engineering B, 132, $113-120$

14. Liu L., Zhang J., Wang H., Guan Z., 2015, Mechanical behavior of the composite curved laminates in practical applications, Steel and Composite Structures, 19, 5

15. Mokhtari M., Madani K., Belhouari M., Touzain S., Feaugas X., Ratwani M., 2013, Effects of composite adherent properties on stresses in double lap bonded joints, International Journal of Mechanics and Materials in Design, 44, 633-639

16. Mukherjee Y.X., Gulrajani S.N., Mukherjee S., Netravali A.N., 1994, A numerical and experimental study of delaminated layered composites, Applied Mechanics Reviews, 28, 837-870

17. Ray C., Majamuder S., 2014, Failure analysis of composite plates under static and dynamic loading, Structural Engineering and Mechanics, 52, 1

18. Rybicki E.F., Kanninen M.F., 1977, A finite element calculation of stress intensity factors by a modified crack closure integral, Engineering Fracture Mechanics, 9, 931-938

19. Shiming C., Xiaoyu S., Zihao Q., 2011, Shear bond failure in composite slabs - a detailed experimental study, Steel and Composite Structures, 11, 3

20. Shishesaz M., Bavi N., 2013, Shear stress distribution in adhesive layers of a double-lap joint with void or bond separation, Journal of Adhesion Science and Technology, 27, 11, 1197-1225

21. Shivakumar K.N., Tan P.W., Newman J.C., 1988, A virtual crack-closure technique for calculating stress intensity factors for cracked three dimensional bodies, International Journal of Fracture, 36, R43-R50

22. Shokrieh M.M., Rajabpour-Shirazi H., Heidari-Rarani M., Haghpanahi M., 2012, Simulation of mode I delamination propagation in multidirectional composites with R-curve effects using VCCT method, Computational Materials Science, 65, December, 66-73

23. Tsai M., Morton J., Matthews F., 1995, Experimental and numerical studies of a laminated composite single-lap adhesive joint, Journal of Composite Materials, 29, 1254-1275

24. Varughese B., Mukherjee A., 1997, Ply drop-off in layered composites-evaluation of design parameters, [In:] Computational Structural Mechanics, Allied Publishers Ltd., 473-482

25. Whiтcomb J.D., 1989, Three-dimensional analysis of a postbuckled embedded delamination, Journal of Composite Materials, 23, 862-889 